\title{
A study of selected properties of autoclaved bricks.
}

\author{
Katarzyna Komisarczyk, , and Ryszard Dachowski \\ Faculty of Civil Engineering and Architecture, Department of Building and Architecture, Kielce \\ University of Technology, Kielce
}

\begin{abstract}
This research investigated the possibility of using material with different share as an addition to prepare autoclaved bricks. Modifiers are searched, thanks to which the obtained materials will indicate potential suitability of modified products for exposure to activity of moisture and highly loaded building elements, e.g. basement walls. As the modifier was used: highly-efficient chemical agent of polymer, silicate and lithium compounds. The amount of water necessary to thicken the mixture was replaced by a modifier. Introduction of modifier in the form of chemical agent into lime-sand mixture causes the increase of the compressive strength by more than $4 \mathrm{MPa}$ in relation to the reference sample, using $1 \%$ of additive. In each analyzed case it reduces the water absorption of finished products. The results of compressive strength and water absorption show different values after 21 days and 24 months from the autoclaving process, the longer the time from the moment of production of products, the better result. Regardless of the amount of applied modifier, the distribution of pores is presented in similar way, the number of macropores was noted at level of around $70 \%$.
\end{abstract}

\section{Introduction}

Request for new materials has contributed to the identification of research and their implementation for common production, which gives completely new opportunities for designers. Working out new materials and the improvement of already existing materials influences the improvement of the quality of life of the society [1,2]. Then ecological materials grow more and more in popularity. First of all lime-sand products, which have additionally high resistance to biological corrosion, prevent the development of fungi and bacterial flora. The article considers sand-lime products, which texture is based on natural components such as: water $\left(\mathrm{H}_{2} \mathrm{O}\right)$, calcium $(\mathrm{CaO})$ and sand $\left(\mathrm{SiO}_{2}\right)$ [3].

The world constantly conducts research, which the main goal is to idicate ways of the improvement of the quality of autoclaved materials. From the literature modifications of basic composition or raw material mixture are known with such additives as: used casting masses [4], granulated blast-furnace slag [5], ground limestone [6], fly ash from brown coal [7], chromium waste [8], landfill leachate [9], glass additives [10], polyethylene glycol [11],

\footnotetext{
* Corresponding author: komisarczyk.kasia@gmail,com
} 
recycled moulding and core sands [12]. Using the polypropylene mesh increased compressive strength by $25 \%$ while decreasing the product density [13].

Additives in the form of recycled plastics have significant influence over the properties of obtained lime-sand products, which are dependent on the type of polymer, the form of recycling and the amount of polymer in the sample. The most favourable parameters were obtained with $20 \%$ of HIPS regranulation, $30 \%$ of HIPS regranulation and $20 \%$ of PP + PE regranulation and their compressive strength in comparison to reference sample increased respectively by $160 \%, 70 \%$ and $48 \%$ and water absorption decreased respectively by: $33 \%$, $93 \%$ and $49 \%$ [14].

Therefore, we are looking for such modifiers, thanks to which the obtained materials will indicate suitability for exposure to moisture and highly loaded building elements, e.g. basement walls. The basic cognitive objective of the research, being the ground of this articles is the evaluation of the possibility of the application of chemical agent additive for obtaining autoclaved lime-sand materials with favourable physical properties. First of all materials with high compressive strength and reduced water absorption. Applied additive in liquid form is highly-efficient chemical agent for the care and sealing of concrete surfaces. Additional modification with polymer binding material provides the maximum level of sealing the concrete by binding components of the concrete matrix that do not contain free compounds of calcium. The substance on the basis of lithium silicate deeply penetrates the layer of concrete and by entering into reaction with free hydroxide of calcium it creates a hard, resistant, tight and coherent structure. The preparation is called Nanoseal, the exact composition is unknown, it is protected by the manufacturer. However, it is available on the market.

\section{Experimental}

Conducting research being the basis of this article, individual series of samples of autoclaved materials were obtained in a fixed and repeatable manner. The research was carried with the cooperation with sand-lime production plant in Ludynia (Poland) belonging to the SandLime Group Corporation. The amount of the mixture of lime and sand was constant. The amount of water added at the moment of mass formation has changed. The water was partially replaced with the additive- highly-efficient chemical agent of polymer, silicate and lithium compounds. The additive in liquid form was dosed in such way that the molding humidity of the mass was maintained at level of $6 \%$. The exact amounts of applied modifier are shown in Table 1. Next so prepared masses were laid into steel, three-field molds, thanks to which samples in the shape of beams of $40 \times 40 \times 160 \mathrm{~mm}$ (height $\times$ width $\times$ length) were obtained. Samples were formed using hydraulic press with method of double-sided one-stage pressing.

Table 1. Dosing the modifier and water.

\begin{tabular}{c|c|c} 
Number of samples & Amount of water [\%] & Amount of additive [\%] \\
\hline R & 5 & - \\
\hline 1 & 4 & 1 \\
\hline 2 & 2 & 3 \\
\hline 3 & - & 5
\end{tabular}

Next the samples were subjected to hydrothermal treatment in industrial autoclaves (Fig. 2), where the following conditions existed: saturated steam pressure 1,6 $\mathrm{MPa}$, steam temperature $203^{\circ} \mathrm{C}$, autoclaving time 9,5 hours. 


\section{Testing methods}

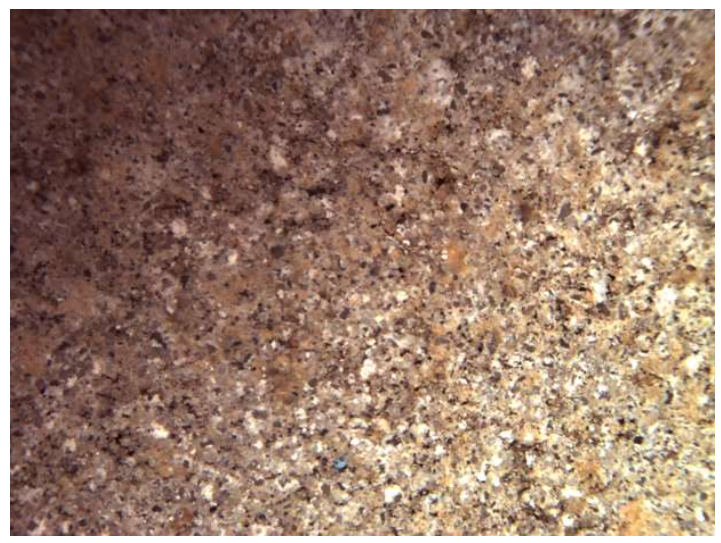

Fig. 1. Image of an autoclaved material ( $5 \%$ modifier) from an optical microscope.

At the initial stage of research, after 21 days from the autoclaving of the materials, the compressive strength (hydraulic press Tecnotest KC 300) and the absorbability were determined. Research was repeated after 24 months. The microstructure of the obtained materials was researched using scanning microscope of the company Quanta 250 FEG equipped with microanalyzer of dispersion of energy of X-radiation EDS. The results of the observation of the microstructure of the samples were recorded in the pictures. The phase composition of the discussed materials was determined with the method of X-ray diffractometry (XRD). Images of the structure of materials were also taken using optical microscope (Fig. 1).

The determination of microporosity and distribution of size of pores of obtained materials was made using method of mercury porosimetry. For this purpose mercury porosimeter of the company Poremaster 60 Quantachrome - USA was used.

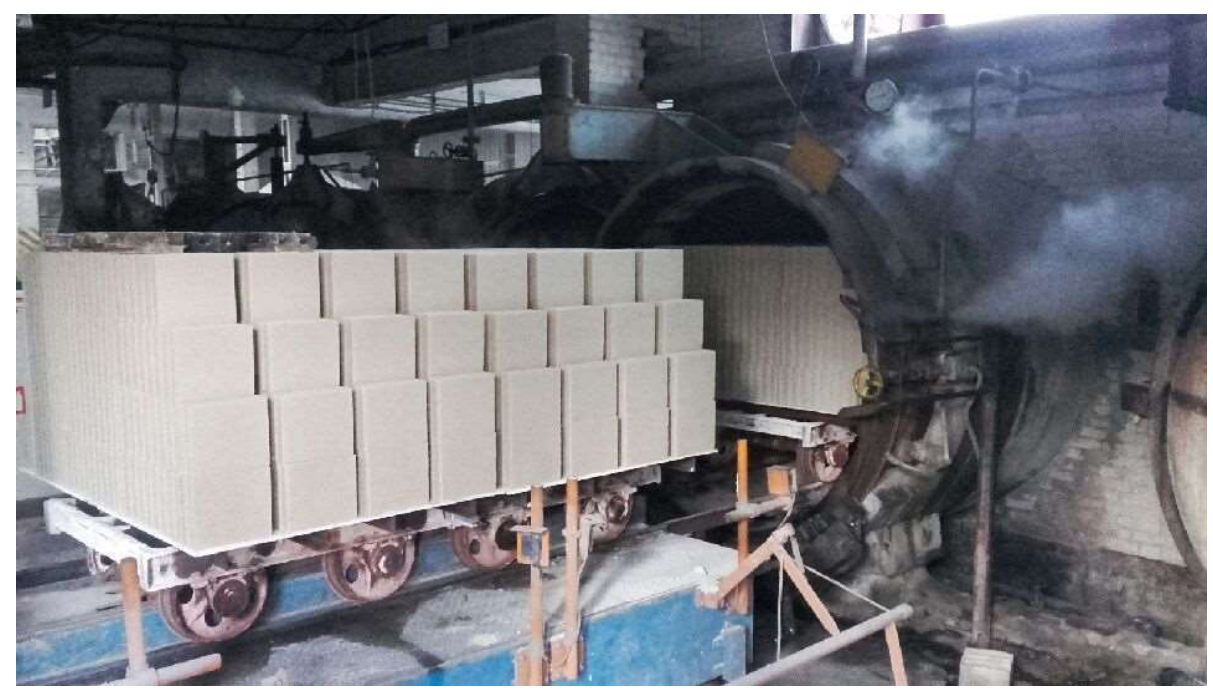

Fig. 2. Specimens subjected to autoclaving process in industrial conditions. 


\section{Results and discussion}

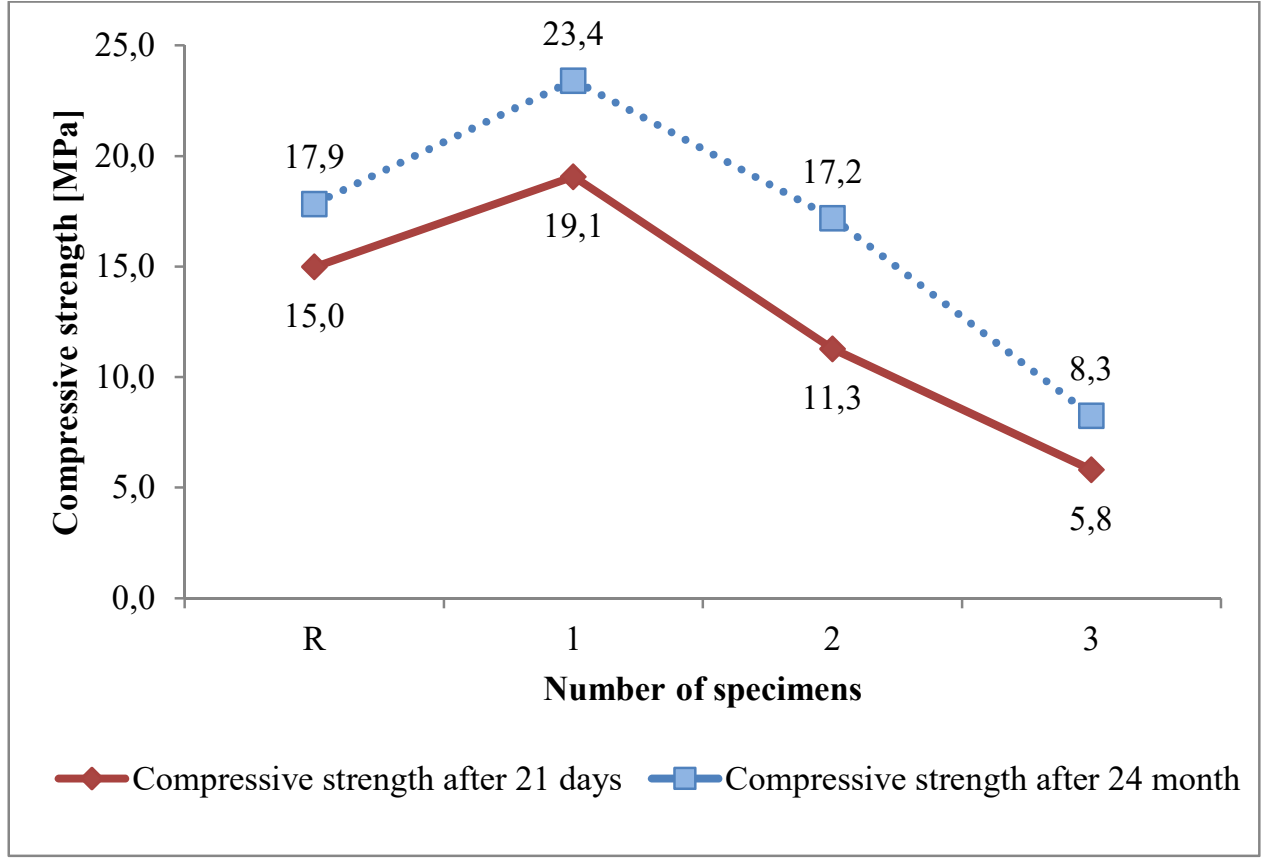

Fig. 3. Compressive strength results after 21 days and 24 month from autoclaving process.

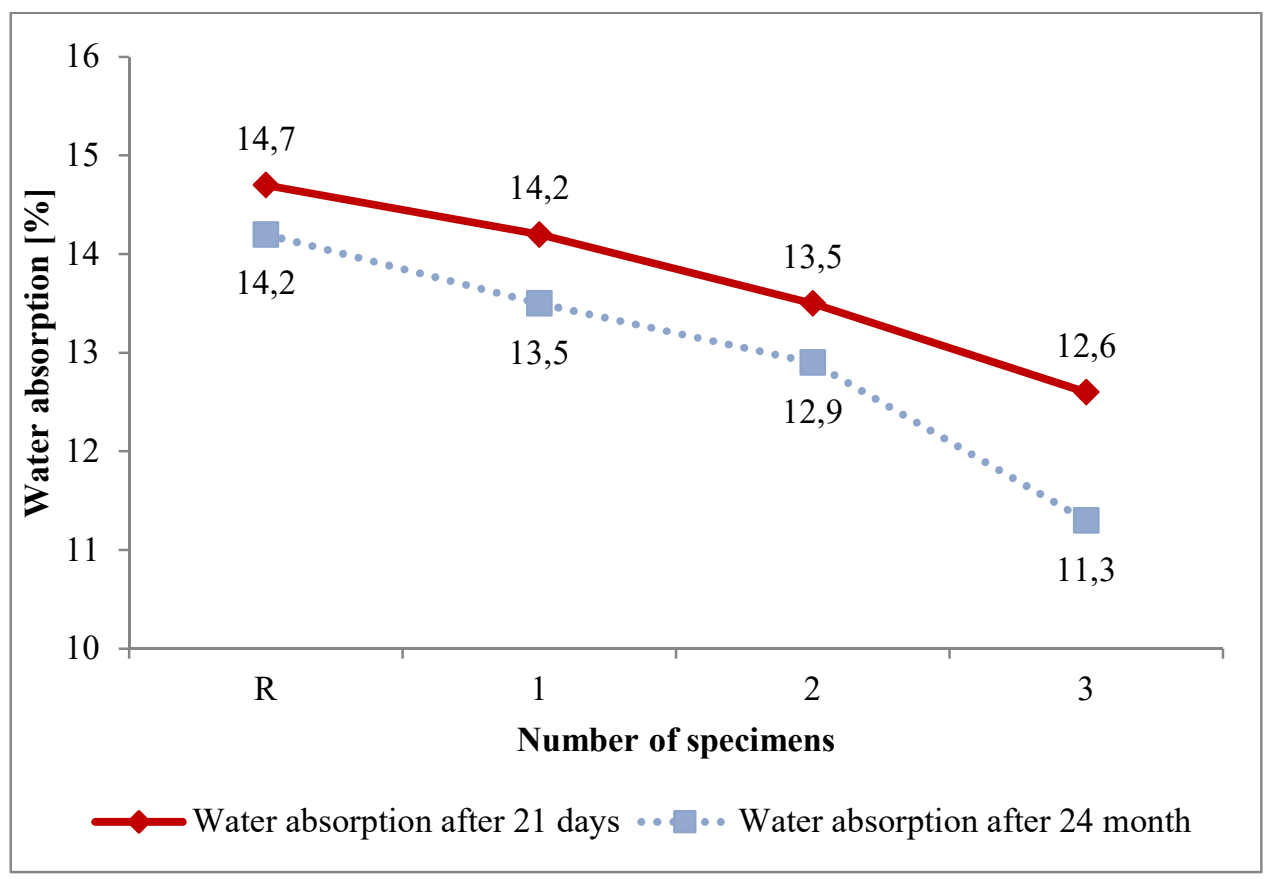

Fig. 4. Water absorption after 21 days and 24 months. 


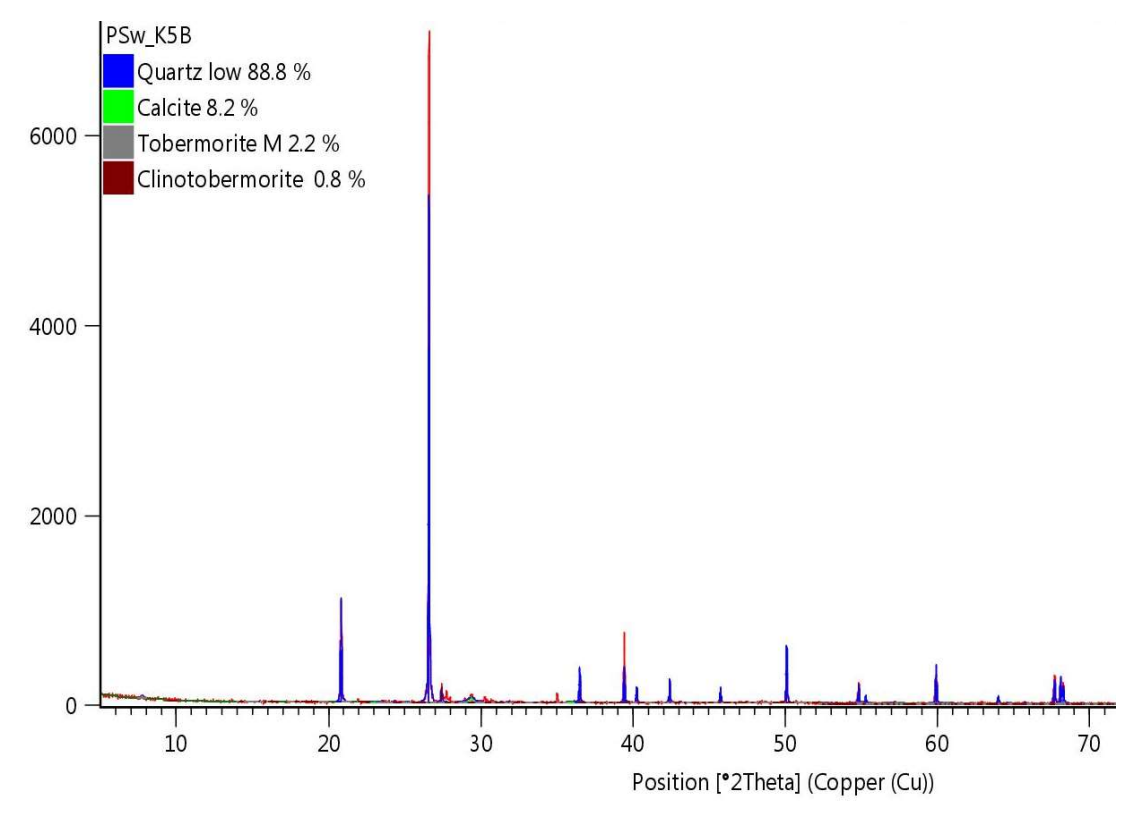

Fig. 5. XRD patterns of specimen 3.

The results of research of physical properties are shown in Fig. 3 and Fig. 4. Analyzing the data contained in Fig. 3, it can be stated that the application of chemical agent affects the different distribution of compressive strength. The addition of $20 \%$ of modifier causes the increase of the strength by more than $4 \mathrm{MPa}$, in relation to the reference sample. However larger than by $20 \%$ and complete replacement of water with chemical agent does not affect favorably the strength of the finished product. In each of the analyzed cases conducted research of compressive strength after 24 months from the autoclaving process show higher values in relation to the primary values. Time improves the compressive strength of silicates. Perhaps compressive strength should be investigated after longer time than 21 days from autoclaving process. In order to confirm the thesis put forward, further tests should be performed.

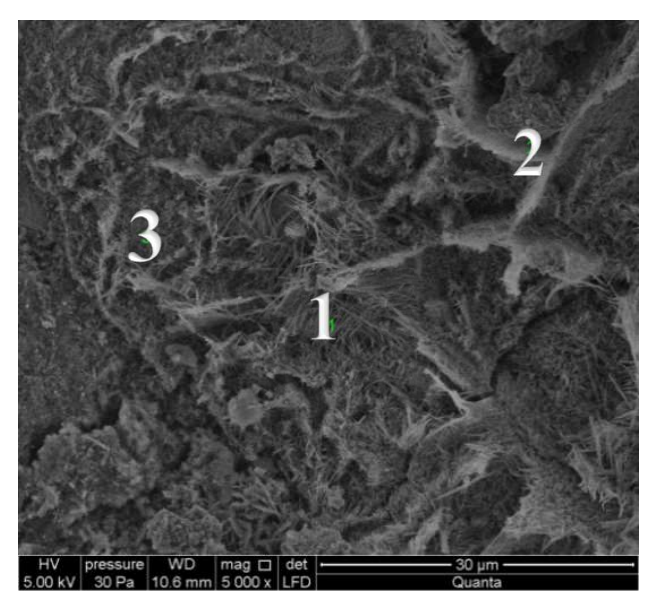

Fig. 6. Microstructure of sand-lime products modified of chemical agent. 


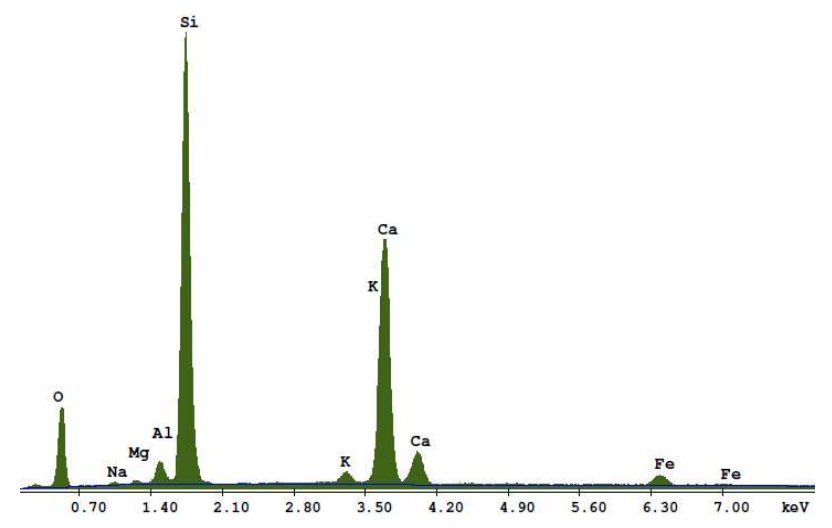

Fig. 7. EDS analysis. Number 1.

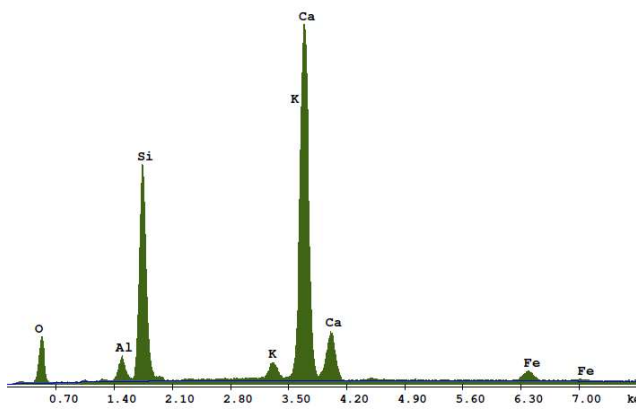

Fig. 8. EDS analysis. Number 2.

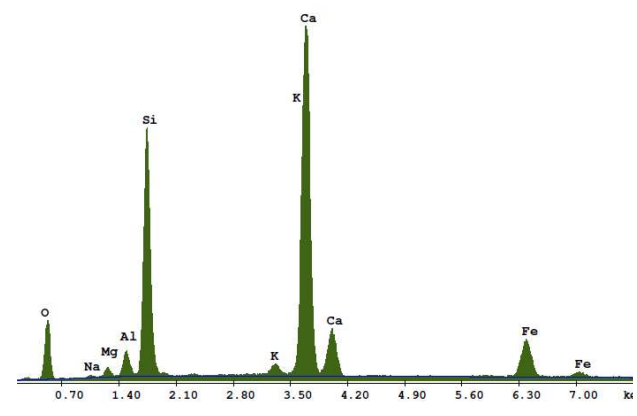

Fig. 9. EDS analysis. Number 3.

Research of the water absorption of the obtained materials proves that the chemical agent influences the improvement of water absorption of finished lime-sand products, according to the assumption. Analyzing Fig. 4 correlation between the amount of introduced modifier and the absorbability of the autoclaved materials can be noticed. Research of absorbality after 24 months from the moment of production of materials influences the decrease of water absorption. Therefore this thesis can be confirmed that silicate materials with the addition of liquid modifier are resistant to the effects of time.

Figure 5 presents the diffractogram of the modified material with $5 \%$ of content of modifier with the indication of the identified phases. Among crystalline phases there are both unreacted initial raw materials in the form of quartz and calcite and products of synthesis: tobermorite and clinotobermorite. Illustrative, but the most characteristic image of the microstructure of the obtained materials, together with the results of analysis in microareas are shown in Figures 6, 7, 8 and 9. In the image of microstructure, typical phases for this type of materials were observed: C-S-H phase and tobermorite. The existence of phases are confirmed by obtained results from the EDS analysis.

The graph (Fig. 10) shows cumulative pore volume curves, depending on their diameter, obtained for the samples in question. On the x-axis (logarithmic) the pore diameters was put $[\mu \mathrm{m}]$. On the y-axis, the volume of porous space occupied by the mercury injected into the sample was placed. The y-axis shows the percent volume of mercury. Total mercury injected into the sample gives the effective porosity of the test sample. The distribution of size of pores in both samples 1 and 3 is very similar. Minimum differences in the distribution of macropores were noticed. Irrespective of the content of the modifier in the form of chemical 
agent, the proportion of macropores (pore diameters greater than $50 \mathrm{~nm}$ according to IUPAC) is at the level of $70 \%$. The presence of macropores in materials is immitent as it is the result of applied method of forming samples. Macropores affect the durability of porous materials. They mainly determine their resistance to low temperatures [14].

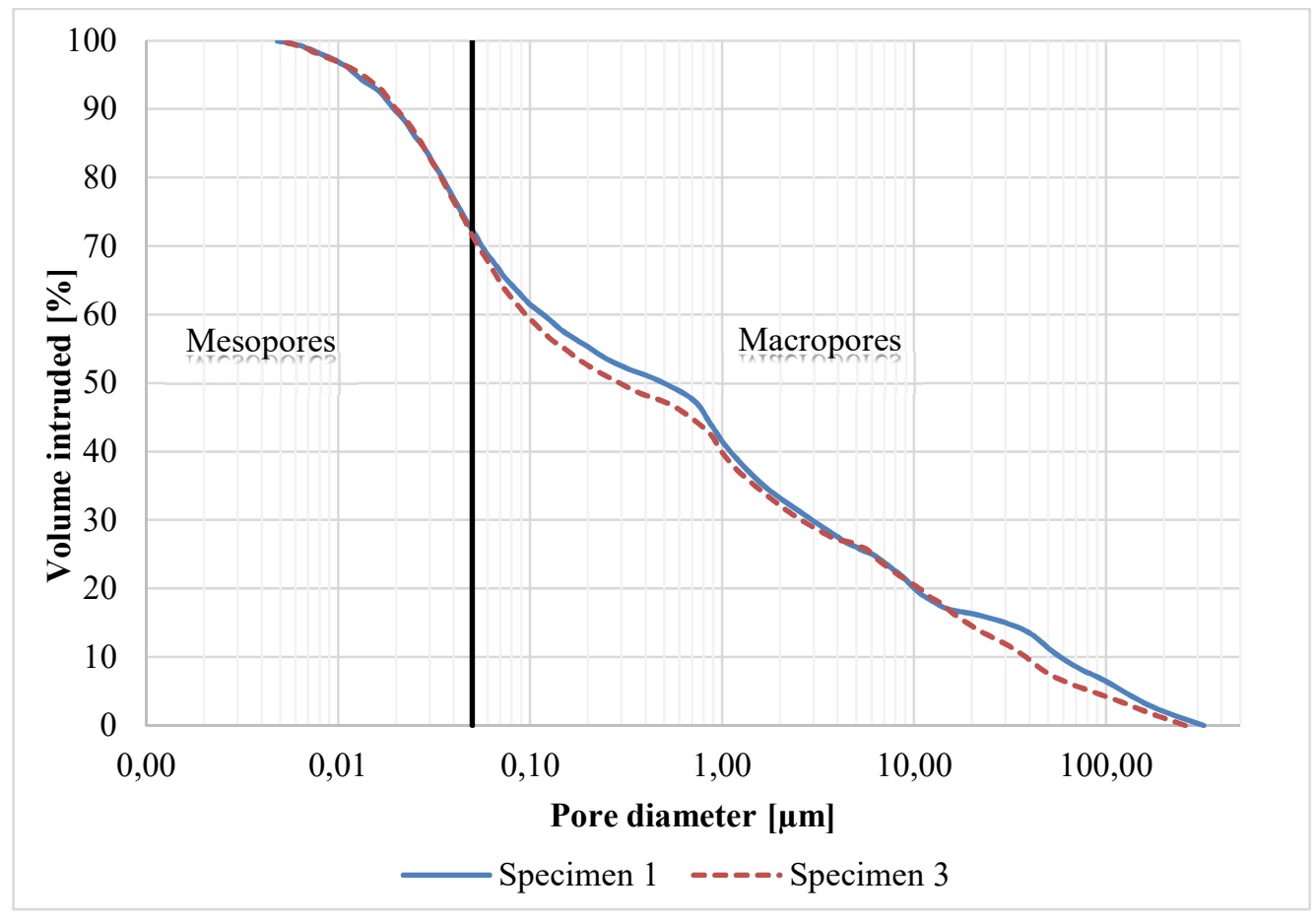

Fig. 10. Content of mesopores and macropores in specimen 1 and 3.

\section{Conclusion}

Introduction of modifier in the form of chemical agent into lime-sand mixture causes the increase of the compressive strength by more than $4 \mathrm{MPa}$ in relation to the reference sample, using $1 \%$ of additive. In each analyzed case it reduces the water absorption of finished products. The results of compressive strength and water absorption show different values after 21 days and 24 months from the autoclaving process, the longer the time from the moment of production of products, the better result. In the image of the microstructure after the application of chemical agent distinct differences in the microstructure are not observed in comparison to this type of materials obtained from initial raw materials. Regardless of the amount of applied modifier, the distribution of pores is presented in similar way, the number of macropores was noted at level of around $70 \%$. 


\section{References}

1. R. Dachowski, A. Stępień, Impact of modification of sand-lime mass with organic compounds on the microstructure and mechanical features of silicate bricks Env. Eng. (2014)

2. G. Mazurek, P. Buczyński, M. Iwański, Optimization of the read binder used in the base layer in the road construction Const. and Build.Mat. 125 (2016)

3. A. Stępien, The impact of barium sulfate on the microstructural and mechanical properties of autoclaved silicate products Env. Eng. 9, 1-6 (2014)

4. Z. Pytel, Properties of autoclaved sand-lime materials obtained with the use of casting sands (in polish) Ach. of Foud. Eng. 10, 2 (2010)

5. Z. Pytel, Properties of sand-lime materials with the participation of granulated blastfurnace slag (in polish) Pol. Cer. Bul.: Cer. 66, (2001)

6. Z. Pytel, The influence of ground limestone on the properties of autoclaved sand-lime materials (in polish) Pol. Cer. Bul.: Cer.91, (2005)

7. Z. Pytel, J. Małolepszy, Properties of autoclaved products containing fly ash from brown coal (in polish) Buil. Cer. 8-14 (1996)

8. Z. Pytel, J. Małolepszy, The structure and texture of sand-lime bricks with additives chromium waste (in polish) Scien. Not. of the Crac. Univ. of Tech. 106, 287-295 (1990)

9. R. Dachowski, M. Nowek Landfill Leachate as an Additive in Sand-Lime Products Proc. Eng. 161, 572-576 (2016)

10. A. Stępień, The impact of glass additives on the functional and microstructural properties of sand-lime bricks Inter. Jo. of Civ. and Env. Eng. 4, 3 (2017)

11. R. Dachowski, P. Kostrzewa Impact of polyethylene glycol on porosity and microstructure of sand-lime product, E3S Web of Conf. 10 (2016)

12. Z. Pytel Evaluation of potential applications of recycled moulding and core sands to production of ceramic building materials Cer. Inter. 40, 4351-4358 (2014)

13. A. Stępień, P. Kostrzewa, Autoclaved Sand-Lime Products with a Polypropylene Mesh Mat. Sc. and Eng. 245 (2017)

14. M. Nowek, Modified sand-lime brick for underground walls, IV Nat. Scien. Conf. Adv. Tech. Ext. and Virt. Real. (2017)

15.Z. Pytel, Cer. 120, 138-140 (2016) 